\title{
A matriz de comportamento do spin doctor no processo de comunicação política
}

THE SPIN DOCTOR BEHAVIOUR MATRIX AT THE POLITICAL COMMUNICATION PROCESS

\section{Vasco Ribeiro}

Doutor em ciências da comunicação pela Universidade do Minho, mestre em comunicação política pela Faculdade de Letras da Universidade do Porto (FLUP) e licenciado em comunicação social pela Escola Superior de Jornalismo. Professor da Faculdade de Letras da Universidade de Porto (FLUP) e professor convidado da Porto Business School. vribeiro@letras.up.pt

Recebido em 20 de março de 2015. Aprovado em 28 de junho de 2015.

\section{Resumo}

Em meados da década de 1980, surgiu nos Estados Unidos uma nova designação para a atividade da assessoria de imprensa política: o spin doctoring. Muito se tem falado dos spin doctors e da sua forma de atuar, mas nem sempre percebemos até que ponto as suas ações se diferenciam do modelo normativo da tradicional assessoria de imprensa. Assim, este artigo propõem-se explanar 36 técnicas, ações e comportamentos que resultam numa matriz de comportamento dessas fontes sofisticadas de informação que operam a serviço de governos, partidos políticos e até mesmo empresas privadas.

Palavras-chave: Spin doctoring. Assessoria de imprensa. Comunicação política.

\section{Abstract}

In the mid-eighties was born a new name for the activity of the political press relations: the spin doctoring. Much has been said of spin doctors and their way of acting, but we do not always realize the extent to which their actions differ from the normative model of the traditional media relations. Thus, this article propose to explain 36 techniques, actions and behaviours that result in a behaviour matrix of these sophisticated information sources operating in the service of governments, political parties and even private companies.

Keywords: Spin doctoring. Media relations. Political communication. 


\section{Introdução}

Foi durante a corrida eleitoral de Ronald Reagan à Casa Branca (contra Walter Mondale), em 1984, que William Safire, jornalista e comentador norte-americano, usou pela primeira vez o termo spin doctor para descrever o comportamento de "uma dúzia de homens em bons fatos e mulheres em vestidos de seda" (SAFIRE, 1984).

O termo que Safire popularizou parece ter nascido da conjugação do "doctor of publicity” (IVY LEE apud EWEN, 1996, p. 84), usado por Ivy Lee com o 'spin', frequentemente utilizado nos artigos de James Reston ${ }^{1}$. Mas pode igualmente ser entendido como mais uma atualização para denominar depreciativamente a assessoria de imprensa política, tal como no passado foram usados os termos spin a yarn, ballyhoo, plutogoges ou flackery (RIBEIRO, 2013).

\section{Primeiros estudos académicos sobre o novo epíteto}

James Tankard e Randy Sumpter (1993, pp. 10-13) foram os primeiros a estudar o termo spin doctor. Realizaram um levantamento de todas as notícias que usaram o termo spin doctor na imprensa norte-americana entre 1982 e 1992 e concluem, entre outros dados, que o spin doctor é "alguém que fica atrás do repórter e da máquina de escrever a tentar determinar a forma como a notícia deve ser escrita". Também Maltese (1992) descreve as assessorias de imprensa políticas entre as presidências norte-americanas de Kennedy e Clinton e introduz uma nova variação ao epíteto - Spin Control.

Mas foi com a chegada de Tony Blair à liderança do Labour, em 1994, que os spin doctors e sua atividade se popularizaram. Importa recordar que os trabalhistas ingleses se encontravam na oposição há 16 anos, além de que a sua imagem estava desajustada face às alterações políticas e ideológicas ocorridas em toda a Europa, após a queda do Muro de Berlim. Neste contexto, Peter Mandelson, então responsável pela comunicação do Partido Trabalhista, o Labour, viu na entrada do novo líder a oportunidade de refundar o partido e de criar uma nova política de comunicação. Dentro desta estratégia, Peter Mandelson decidiu também contratar Alastair Campbell, seu amigo e editor de política do Today, para porta-voz do partido e escolheu a rosa como novo símbolo dos trabalhistas. Nasceu, assim, o New Labour (LOUW; ERIC, 2010).

1 James Reston, antigo jornalista e editor de política do New York Times, usou sempre o verbo 'to spin' para descrever as manobras políticas do presidente dos EUA, Dwight Eisenhower, ainda durante os anos 1950 (RESTON, 1955, 1961). Mas este antigo prémio Pulitzer foi usando sempre o termo "spin" nos seus artigos políticos (RESTON, 1981ª 1981b) muito antes de Willian Safire. 
Ainda antes da corrida eleitoral de 1997, na qual Tony Blair chega a primeiro-ministro, já abundavam na imprensa britânica notícias sobre o trabalho da dupla Mandelson e Campbell. Notícias essas em forma de "guia" sobre como lidar com essa "nova" atividade, como é o caso dos artigos Doctors in the House (JONES, 1995) ou Trust me, I"m not a spin doctor (LANGDON, 1995), ou a demonstrarem já alguma inquietação pela forma como os spin doctors atuavam com os jornalistas: Spinning out of control? (CRAING, 1996), Spin, whores, spin (LANGDON, 1996), Making a name in politics (WHITE, 1996), Party free or pati pris? (PRESTON, 1997), entre muitos outros.

$\mathrm{O}$ termo começou a circular entre os leitores da imprensa política e rapidamente se propagou pela população britânica, tendo o próprio Campbell chegado a desabafar: "Até mesmo a minha mãe me perguntou no outro dia o que era um spin doctor. Portanto, sabe Deus a ideia que as pessoas fazem disto" (ALASTAIR CAMPBELL apud PRESTON, 1996). Campbell tinha razões para se preocupar com a reputação, pois, para o comum britânico, o spin doctor é alguém que se situa entre "um assaltante, um passador de droga e um agente de imobiliária" (RICHARDS, 2005, p. XI), alguém que "oferece um whisky novo como sendo velho" (STARK, 2000, p. 4), ou, na melhor das hipóteses, "uma forma eufemística de chamar manipulador" (ANDREWS, 2006, p. 32).

Os spin doctors eram quase sempre descritos, nas colunas dos jornais britânicos, como "príncipes das trevas", "lado negro da força", "demónios", "agentes da escuridão", "sombras", "mestres das artes negras", "maquiavélicos", "mentirosos" e "manipuladores". Estes termos negativos são também amplamente usados por vários investigadores da sociologia do jornalismo, que procuram compreender o spin doctoring e seus efeitos (DAVIS; 2003; FRANKLIN; 2003; MANNING; 2010; MCNAIR; 2003, 2004; SCHLESINGER, 2001, 2006; SEYMOUR-URE, 2003).

O spin abandona, assim, o sentido inicial de James Reston e passa a ser um eufemismo de engano.

O spin é um bordado de uma verdade num tecido de mentira com vista à produção de uma peça de roupa vistosa mas que também proteja ou oculte a crítica pública (FITZWATER, 1995, p. 220).

Os spinners induzem em erro por meios que vão desde as omissões às subtis mentiras. Pintam um retrato falso da realidade por enviesamento dos factos, descaracterizando as palavras, ignorando ou negando provas cruciais, ou apenas "spinning a yarn" (BROOKS, 1999, p. VII)

O trabalho dos spin doctors é o de antecipar-se a uma tendência desfavorável, introduzindo por vezes uma favorável, permitindo uma poderosa manipulação e distorção do processo democrático (STREET, 2011, p. 10). 
Em Portugal, Nelson Traquina (1993b, p. 14) foi pioneiro a definir esta atividade, vendo-a da seguinte forma: "o velho mas agora renovado, modernizado e totalmente indispensável trabalho propagandístico de querer influenciar a cobertura jornalística, certificada pela recente designação dos chamados spin doctors ”. Mais tarde, Vasco Ribeiro (2009) dá o título a uma obra onde encaixa os spin doctors - Fontes Sofisticadas de Informação.

No Brasil, a dupla de pesquisadores da Universidade Federal de Santa Catarina, Aldo Schmitz e Francisco Karam, foram os primeiros a avaliar o spin doctoring nas fontes das notícias e apresentaram uma interessante definição:

Os spin doctors são profissionais de comunicação, capazes de forjar a opinião pública utilizando-se dos processos, dos procedimentos, da cooptação de jornalistas e do saber do jornalismo e das relações públicas, para ter sucesso na mídia ou diretamente com seu público alvo (SCHMITZ; KARAM, 2013, p. 98).

\section{Matriz de comportamento do "spin doctor"}

Mesmo sabendo que um spin doctor assume uma particular adaptação ao cargo, se juntarmos as diferentes ações, comportamentos e "casos" descritos por vários autores e investigadores (BROWN, 2003; DAVIS, 2002; FRANKLIN, 2003; FRANKLIN; AL, 2009; GABER, 2000, 2007, 2010; MANNING, 2001; MCNAIR, 2003, 2004; MILLER; DINAN, 2008; PEARSON, 2009; RICHARDS, 2005; SCHLESINGER, 2006; SERRANO, 2010; SUMPTER; TANKARD, 1994), conseguimos tornar visível uma matriz identitária que nos poderá ajudar a compreender e a definir estes agentes ao serviço da comunicação política.

Decidimos, então, distribuir esta matriz identitária por quatro grandes grupos, de forma a compreender quais são os grandes objetivos dos spin doctors, os pré-requisitos profissionais para o exercício da atividade, os principais momentos e as principais técnicas da sua sofisticada operação.

\section{Os grandes objetivos}

\section{Definição e condução da agenda mediática}

A condução da agenda mediática é um processo que passa por alimentar os jornalistas com a estória certa, assim como por fornecer as fontes que a validem. "Entregar criteriosamente um exclusivo (ou furo), a par com o fornecimento de uma série de estórias relacionadas, garante que a estória [principal] se mantenha inalterada". (GABER, 2000, p. 269; GREVE, 2000, p. 12). 


\section{Construção de uma personalidade política}

Um spin doctor escolhe as suas peças e movimenta-as no tabuleiro mediático em função dos seus interesses (ou dos do partido). Num parlamento, cabe-lhe decidir - ou, pelo menos, influir fortemente - a escolha de quem será o comentador/entrevistado de uma determinada peça. Com alguma regularidade, este perito em comunicação aposta e potencia um jovem ator político, tentando levá-lo até o mais alto cargo público (SABATO, 1993; p. 70-71).

\section{Vitória em eleições}

Frank Esser, Carsten Reinemann e David Fan (2000) estudaram as notícias geradas através de spin doctoring durante as campanhas eleitorais na Alemanha e no Reino Unido, tendo percebido que a ação destes profissionais dividia-se em duas grandes categorias: 1) "as atividades não relatadas pelos media" e 2) as "atividades diretamente relatadas pelos media". O spin doctor é uma das peças principais numa campanha eleitoral. (ESSER et al., 2000, p. 228).

\section{Manutenção do poder/Campanha permanente}

Não perder o poder é, sem dúvida, outro dos principais objetivos dos spin doctors. Há autores que intitulam esta ação de garantir reeleições a "campanha permanente" (BLUMENTHAL, 1980; BLUMLER, 1990; ORNSTEIN; MANN, 2000) e que em tudo se enquadra na atividade de um spin doctor. O livro The permanent campaign and its future, coordenado por Norman Ornstein e Thomas Mann (2000), reflete e denuncia pragmaticamente esta faceta, pois relata casos de spin doctoring das administrações norte americanas desde Nixon a Clinton.

\section{Pré-condições}

\section{Conhecimento profundo dos temas que aborda e das áreas que representa}

Sendo conhecedor profundo de todos os dossiês e temas/iniciativas do seu partido ou ministério, o spin doctor consegue estar preparado para alimentar os jornalistas com novas estórias e também responder a todas as questões com pleno domínio dos assuntos. Os jornalistas apreciam e avaliam muito essa qualidade dos spin doctors (MANNING, 2001, p. 113), que valeu, por exemplo, ao press secretary de Bill Clinton, Mike McCurry, o enaltecimento pelos media norte-americanos (KURTZ, 1998).

\section{Conhecimento profundo das redações}

Uma atualizada agenda de contactos é fundamental para "vender" uma notícia ou negociar uma revelação, sempre através de contacto pessoal ou telefónico e nunca, como acontece na assessoria tradicional, por meio de press releases. Um spin doctor deve, 
inclusivamente, perceber como cada jornalista político gosta de moldar sua notícia, de modo a poder alimentá-lo com a informação que mais aprecia ${ }^{2}$. Deve ainda ter um bom conhecimento das políticas da redação, incluindo as hierarquias internas da organização noticiosa.

\section{Proximidade com o político que representa}

Quanto maior for a proximidade entre o spin doctor e o assessorado, melhor funciona a cadeia de pensamento e consequente execução da estratégia política. Não chega saber o que o político "faz ou vai fazer", importa também saber o que pensa sobre este ou aquele tema. Os jornalistas avaliam a competência e, até mesmo, a utilidade do spin doctor muito pela capacidade de antecipação das medidas ou decisões políticas.

\section{Grandes orçamentos}

Estes profissionais são sempre sinónimo de grandes orçamentos, quer pelos vencimentos que geralmente auferem, quer pelos serviços que contratam. Em todos os países, há acusações sobre o volume de investimento em campanhas publicitárias às medidas do governo, mas os partidos também não ficam atrás.

\section{Monitorização e reação/capacidade de controlar}

A obsessão pelo controlo de tudo quanto sai na imprensa é uma característica sempre presente no spin doctoring. Por isso, os gabinetes governamentais ou de partidos da oposição têm um ou mais técnicos a gerir o clipping ${ }^{3}$ de tudo quanto é difundido e publicado. Hoje, os recortes de imprensa são muito utilizados para partilhar nas redes sociais.

\section{Preferência pela "sombra"}

Impressionante é o facto de toda esta atividade ser exercida sem que o público o percepcione nas notícias. Vasco Ribeiro (2009) analisou o noticiário político da imprensa diária portuguesa, entre 1990 e 2005, e só detetou a presença explícita de assessores de imprensa e spin doctors em 1,3\% das notícias, facto que faz jus ao rótulo de "homens-sombra" muitas vezes colado a estes profissionais. "É na invisibilidade dos seus esforços que radica grande parte do triunfo destes profissionais" (AIRA FOIX; PASTOR PÉREZ, 2012, p. 5).

2 Está técnica já tinha sido identificada em 1976 na obra Creating reality, de David Altheide, nomeadamente nos jornalistas do lobby do parlamento britânico (ALTHEIDE, 1976, p. 117).

3 Recolha e gestão dos recortes de imprensa (impressos e on-line), assim como das peças de televisão e rádio. 


\section{Capacidade de lobbying}

O lobbying e a sua profissionalização - por altura dos anos 50, quando os governos começaram a privatizar diversos sectores da economia (HARRIS, 2001) - são duas das facetas maquiavélicas ${ }^{4}$ do spin doctoring, uma atividade semissecreta que cruza política, relações públicas, marketing e interesses financeiros e que, no caso dos spin doctors, está muito associada ao controlo editorial, através da cedência de interesses estratégicos aos proprietários das empresas de comunicação social (SEYMOUR-URE, 2003).

\section{Principais tarefas do processo de "spinning"}

\section{Encontrar a mensagem}

É um processo com um conjunto de passos na busca da mensagem ideal para ser anunciada por um político numa conferência de imprensa ou num congresso (GABER, 2000). No fundo, trata-se de identificar os temas que dominam ou preocupam a opinião pública, num procedimento meticuloso que raramente é empírico. O quase obrigatório recurso a empresas de sondagens e análise de mercado ajuda a encontrar os indicadores que moldam a mensagem final e que será usada como base, não só nas intervenções, mas também em todo o trabalho legislativo, eventos, reuniões, audiências, visitas e outras ações políticas.

\section{Elaboração de discursos (speechwriter)}

Os discursos dos detentores de altos cargos políticos, principalmente de governação, raramente são escritos pelos próprios e quase nunca são proferidos de improviso. Cabe ao spin doctor escrever o texto que vai ser lido. Segundo o exemplo de Ivor Gaber (2000), a mensagem é procurada, três dias antes, nos jornais de referência, com particular atenção aos artigos de opinião, onde são identificados pedaços da ideia-chave.

\section{Gestão da imagem (image management)}

Por imagem pública entende-se uma ideia ou um conjunto de atribuições qualitativas que a opinião pública tem sobre um determinado político. Importa referir, a propósito, que a imagem pública é o resultado da soma da imagem real (identidade, valores intrínsecos) com a imagem projetada (identidade visual, cultura e comunicação) (VILLAFAÑE, 1993).

4 Para Blumler (1990, p. 109) o maquiavelismo desta atividade reside no facto de a noção de liberdade de pensamento e debate de ideia ser uma pura ilusão. 


\section{"Fugas-plantadas"}

Sabe-se que não há altruísmo no jornalismo, podendo mesmo existir "tendências contrárias, como vingança, despeito e hipocrisia" (GOLDING; BENS; MCQUAIL, 2005, p. 160). Assim acontece, também, no universo das fontes (FISHMAN, 1980; TUCHMAN, 1978; TUNSTALL, 1974). Por isso, se a informação que circula tem um objetivo específico e serve um determinado fim, as fugas de informação também não são um processo descontrolado e inconsequente. Para os spin doctors, bem como para todas as outras fontes profissionais e políticas, a gestão das fugas de informação é uma das suas mais importantes ferramentas.

\section{Instrumentalização política da máquina governamental}

Logo que um spin doctor conquiste o poder, inicia um processo de instrumentalização das estruturas do Estado. Tanto Bernard Ingham ${ }^{5}$ como Alastair Campbell ${ }^{6}$ foram acusados de usar os organismos governamentais a serviço dos interesses e das estratégias dos partidos que representavam. No Reino Unido chamam a esta prática de "milkanization", numa associação ao nome do edifício onde funciona a máquina governamental de comunicação britânica e que já teve várias denominações: COI, GIS e GIGS.

\section{Debates televisivos}

Não foi por acaso que o termo spin doctors nasceu de uma descrição de um debate televisivo entre Reagan e Mondale, em 1984. De resto, a vulgarização do termo na comunicação social ocorreu também depois de um debate televisivo, desta feita entre Bush e Dukakis, em 1988. O spin doctoring está, pois, e desde sempre, associado a debates políticos na TV (SCHROEDER, 2008). Os debates são momentos de "televisão de alto-risco" (Ibid.) e têm três fases distintas no processo de spin doctoring: o pré-debate, o debate e pós-debate.

\section{Congressos}

Para Stanyer (2001), é como organizar uma festa. Sob a égide dos spin doctors, "donde grande parte das notícias sobre o governo têm origem" (STANYER, 2001, p. 12), também são organizados congressos políticos como se fossem eventos triviais (STANYER, 2001, p. 6). Trata-se de um media event (DAYAN; KATZ, 1992) tanto do agrado de spin doctors como de editores de política, principalmente os de televisão. Mas

5 Antigo assessor de imprensa de Margaret Thatcher.

6 Antigo assessor de imprensa de Tony Blair. 
quem define as regras são os primeiros, uma vez que escolhem o dia e os horários do evento e o adaptam aos conteúdos das televisões.

\section{Personalização do ator-político}

O mesmo James Stanyer, um dos maiores investigadores dos efeitos da personalização na política, defende que esta tendência pode ser materializada de duas formas: através da individualização (individualization) e do intimismo (privatization). O primeiro modelo ocorre quando os políticos usam suas características pessoais para se sobreporem à ideologia do partido que representam ou das lutas políticas que travam. O segundo verifica-se quando o político expõe a sua vida privada, familiar e íntima em vez da ideologia e linha política que segue (AELST; SHEAFER; STANYER, 2011, p. 9).

\section{Gestão de escândalos}

John Thompson (2000, p. 13) descreve escândalo como "uma ação ou um evento que envolve um certo tipo de transgressões, que se tornaram conhecidas para terceiros e que são suficientemente graves para uma lícita resposta pública”. Justo Villafañe (1993, p. 303) prefere chamar-lhes "crise de honorabilidade", associando-os a "casos de corrupção, suborno, seduções" e outros crimes que afetam e deterioram a imagem de indivíduos e empresas de forma irreversível.

\section{Principais técnicas e instrumentos}

\section{Marketing}

As ferramentas de marketing, nomeadamente as de disciplinas mais estratégicas, são vitais para a atividade de um spin doctor, não só em campanhas eleitorais (HARRIS, 2000) como no governo (MALTESE, 1992). O marketing vai, aliás, ao encontro das principais regras do packaging politics. Segundo este princípio, um político deverá ser promovido de acordo com a máxima do marketing mix: produto, preço, distribuição e comunicação. A definição de públicos-alvo e sua consequente segmentação também é uma prática habitual (SEVIN; KIMBALL; KHALIL, 2011).

\section{Redes sociais e buzz media}

Já nos anos 1990, os spin doctors se distinguiam dos outros assessores de imprensa por recorrerem às novas tecnologias (SUMPTER; TANKARD, 1994, p. 24). O spin doctor é um perito em buzz media ou conta com um punhado de bloggers pagos para escrever e apoiar medidas governativas (GREVE, 2005, p. 12). Alimentar redes sociais e organizar equipas que escrevam em sites e telefonem para os programas de antena aberta 
da televisão e da rádio são outras das atividades regulares de um spin doctor (LOUW, E., 2005, p. 166).

\section{Usar os graus de confidencialidade a seu favor}

Melvin Mencher (1991), investigador e antigo diretor do New York Times, e Stephen $\mathrm{Hess}^{7}$ (1984), antigo repórter da Casa Branca e o primeiro autor a estudar o modus operandi dos assessores de imprensa, distinguem diferentes níveis de identificação das fontes ou de atribuição da informação, de acordo com os compromissos assumidos pelo jornalista: on the record (atribuição direta, para publicação), off the record (confidência total), on background/not for attribution (atribuição com reserva) e on deep background (atribuição com reserva total). Quando usados de forma estratégica, estes graus podem, preventivamente, travar eventuais notícias negativas ou evitar a perda de notoriedade de um determinado político.

\section{Campanha negativa}

Uma campanha negativa consiste em atacar invariavelmente um opositor com informações, mais uma vez em forma de fugas de informação, obtidas junto de instituições privadas, de entidades públicas ou de agremiações secretas. Dirty Politics - Deception, Distraction, and Democracy, de Kathleeon H. Jamieson (1992), é uma das obras de referência sobre as campanhas negativas e foi desenvolvida com base numa análise à administração de George Bush (pai).

\section{Manipulação da verdade}

A norma central que estrutura o relacionamento com os jornalistas é a proibição de mentir (BROWN, 2003, p. 6; HESS, 1984, p. 24). Como disse um assessor de Bill Clinton, Lanny Davis, o spin doctoring que usa a mentira "não é só desonesto, é ineficiente" (In Press, 2001, p. XXII). Mas esta regra funciona de forma diferente em ambos os lados da relação. Para o jornalista, o material de base na produção de uma notícia é o que eles próprios assistiram/captaram ou o que as fontes contaram, mas sempre com a possibilidade de interpretar os factos e as informações (que as fontes forneceram) de maneira diferente e, até mesmo, contrária. Para o spin doctor, como nunca é parte visível na notícia, o ato simples de libertar uma informação - quase sempre como fonte secundária

7 Na obra de Hess, Government/press connection (1984), pode ler-se na íntegra uma cópia de um fax-circular enviado pelo então chefe do gabinete de imprensa do Departamento de Estado norte-americano, Rush Taylor, para todos os gabinetes de imprensa governamentais dos EUA onde se ensina a usar estes graus de confidencialidade (HESS, 1984, p. 118-119). 
- não o responsabiliza por completo, porque carece sempre de "validação" e "contraditório" (práticas obrigatórias no bom jornalismo).

\section{"Paraverdade" e over-promising}

“A verdade fria e factual é aborrecida e, muitas vezes, não é credível. [...] Há uma zona ambígua que rodeia a realidade da promessa e se situa algures entre a verdade e a verosimilhança [...]. Esta zona é a paraverdade, ou seja, encontra-se perto da verdade sem merecer, de facto, esse rótulo" (HAUSER, 1999). Exemplo máximo da presença da publicidade, esta técnica representa o princípio de ação (mensagens, discursos, eventos, etc.) que anda sempre no limiar da verdade e da mentira. $\mathrm{O}$ arredondamento dos números (MAAT, 2007, p. 68), a hipervalorização da "cacha" (GEWIRTZ; DICKSON; POWER, 2004, p. 88-90) e a projeção artificial das imagens de candidatos (STANYER, 2013, p. 129) são os exemplos mais frequentes de "paraverdade" postos em prática pelos spin doctors.

\section{Selecionar prioridades nas respostas aos pedidos de informação}

Contrariamente ao que defende Paul Manning (2001), um spin doctor não atende obrigatoriamente a todas as chamadas telefónicas ou responde a todos os pedidos de informação. Tem de estar disponível numa lógica estratégica, que passa pela seleção prudente de tudo quanto informa. Ao não atender criteriosamente algumas chamadas, evita ser forçado, por exemplo, a confirmar/validar uma informação que poderá ser negativa para o político ou para o partido.

\section{Criar um "grupo próximo" de jornalistas}

O jornalismo especializado caracteriza-se por potenciar artigos com mais qualidade, produtividade e profusão. Porém, como reverso da medalha, cria maior proximidade (e promiscuidade em alguns casos) com a fonte (GANS, 1979). Um spin doctor partidário ou governativo possui sempre uma enorme quantidade de informação noticiável para oferecer aos jornalistas mais próximos (projetos legislativos, medidas governativas, disputas internas etc.), por isso, procura criar um "grupo de confiáveis amigos" que vão sendo alimentados/premiados abundantemente com estórias que marcam a ordem do dia (GREVE, 2005, p. 12; OBORNE; WALTERS, 2004, p. 191).

\section{Encontros informais (background meetings)}

Desde os primeiros estudos sobre o relacionamento entre fontes e jornalistas que os encontros informais aparecem como um importante meio de indução de notícias 
(SIGAL, 1973; TUNSTALL, 1970). Assim como, noutra perspetiva, sabemos que, ao contrário dos jornalistas que têm de trabalhar sempre numa lógica coletiva, as fontes podem e atuam sozinhas (TUCHMAN, 1978). Partindo destes axiomas, os encontros informais são os momentom em que as fugas são libertadas como se tratasse do embornal dos jornalistas (KURTZ, 1998).

\section{Manobras de diversão (firebreaking)}

Trata-se de construir deliberadamente um facto mediático, com recurso a uma fuga que desvie a atenção dos jornalistas de uma determinada cobertura mais embaraçosa ou negativa (GABER, 2000). Eric Louw (2005) diz mesmo que os spin doctors chegam a libertar informação que não corresponde à verdade só para desviar atenções (LOUW, 2005, p. 164-166).

\section{Esvaziamento da estória}

Sabendo que está a ser preparado um artigo negativo - muitas vezes resultado de um longo período de investigação jornalística -, o spin doctor antecipa a estória fornecendo-a paralelamente a um outro órgão de comunicação social ou, por vezes, fazendo uma conferência/declaração de antecipação à imprensa (MICHIE, 1998). Uma técnica que decorre da comunicação de crise e que se define como uma "preparação para o impacto" ou uma minimização de danos. De facto, uma determinada versão contada pela vítima ou pelo adversário não tem o mesmo tratamento e enfoque (VILLAFAÑE, 1993, p. 305).

\section{Testar a opinião pública (kite-flying ${ }^{8}$ )}

Consiste em fazer passar uma informação que teste seu grau de aceitação junto da opinião pública, mas sem revelação das fontes de informação. Caso a informação seja contestada - por grupos corporativos, profissionais, sindicatos etc. -, o Governo apressa-se a desmentir a notícia. Nelson Traquina salienta que as fugas de informação funcionam como "balões de ensaio" para testar a reação da opinião pública (TRAQUINA, 1993ª p. 173).

\section{Aumentar ou diminuir as expectativas}

Atividade muito associada ao período de aprovação do Orçamento de Estado, passa, tal como o nome sugere, pela "sobrevalorização" ou "subvalorização" de dados em função do objetivo específico. Se um político assumir antecipadamente que uma

8 Esta expressão significa também usar um cheque ou recibo de forma fraudulenta. 
determinada ação pode resultar num fracasso, tirará um duplo proveito: 1) Se correr mal, antecipado e já noticiado que foi, não o prejudicará sobremaneira; 2) Se correr bem, poderá recolher os resultados de ter invertido o inevitável.

\section{Informação a conta-gotas (milking a story)}

Os exclusivos de uma ação governativa ou iniciativa legislativa raramente são fornecidos na totalidade ao jornalista, porque isso iria esgotar a notícia. Fornecer fragmentos de informações a vários (não muitos) órgãos de comunicação social permite uma maior cobertura - em destaque porque foi "vendido" como "cacha" - e por vários segmentos de público, quando se reparte a informação em função do suporte e das características editoriais (GABER, 2000).

\section{"Esconder os corpos" (throwing out the bodies)}

Todos os governos têm necessidade de tornar públicas informações negativas para a sua reputação ou notoriedade. Aproveitando as dezenas de releases que são difundidos diariamente pelas redações ou pelos jornalistas que "moram" nas galerias do parlamento, o spin doctor avança de permeio com essas informações menos populares. Um exemplo paradigmático desta técnica foi o comportamento da assessora de imprensa do ministro dos Transportes de Tony Blair, Jo Moore, quando sugeriu que o dia do atentado às Torres Gémeas era um "um bom dia para largar qualquer coisa que queremos enterrar" (YANTAO, 2012, p. 124).

\section{Bullying e intimidação}

Pressão que passa por, conscientemente, forçar o jornalista a continuar a ser leal aos enquadramentos, às fontes e ao timing das notícias vendidas pelo spin doctor. Perante notícias negativas, o spin doctor deve mostrar com clareza o seu desagrado aos responsáveis pelas mesmas - o que, por vezes, pode traduzir-se em manobras de intimidação sobre os jornalistas (FRANKLIN, 2003; GABER, 2000; MANNING, 2001). Perante informações hostis reagem pela regra dos três Rs: retórica, refutação e repetição ( CHRISPHERSON apud FRANKLIN, 2004, p. 69).

\section{A difícil definição de spin doctoring}

Sabe-se que o termo tem sofrido graduações de negatividade ao longo das duas últimas décadas e por isso, na atualidade, parece ter ficado mais suave ou, dito de outra forma, menos pejorativo. Parece, todavia, não haver dúvidas de que quando um comentador, 
jornalista, ativista ou político pretende descrever a atividade de um assessor de imprensa político lhe chama, quase invariavelmente, spin doctor ou refere o spin, spinning ou spin doctoring da sua ação.

Sabemos que não existe uma definição universal, e muito menos consensual, para spin doctoring. Mas, ainda assim, arriscamos a definir spin doctoring como a projeção positiva para o espaço público de um determinado sujeito ou ação, através das mais sofisticadas e atualizadas técnicas de manipulação e persuasão. Neste processo destacam-se os media como canal preferencial para a distribuição e indução de mensagens, tendo como motor o relacionamento interpessoal com os jornalistas.

\section{Conclusão e discussão}

A leitura deste artigo torna óbvia a imagem pouco abonatória que os spin doctors têm, não apenas entre os jornalistas, mas também junto da opinião pública em geral. De facto, são muitos e nada simpáticos os epítetos atribuídos aos assessores de imprensa que, inseridos na dinâmica política, desenvolvem ações tipificadas na presente matriz. E compreende-se porquê. Os mais competentes têm uma influência substantiva no processo noticioso, enquanto fontes próximas dos vários poderes (político, económico, social, cultural etc.) e, por isso, com capacidade para alimentar grandes estórias. Acontece, porém, que estas fontes nem sempre estão comprometidas com a verdade. Ou, pelo menos, são capazes de criar um efeito ilusório que se abeira, perigosamente, da manipulação de factos ou mesmo da mentira rotunda.

Voluntária ou involuntariamente, os políticos veem sua ação pública e seu pensamento ideológico, quando este existe, condicionados por imperativos de gestão da imagem. Imperativos esses que decorrem, muitas vezes, das estratégias de comunicação traçadas pelos spin doctors. Mutatis mutandis, os erros de gestão política e os próprios atos ilícitos cometidos no exercício de cargos públicos são alvo de processos de branqueamento através dos media, por ação justamente dos spin doctors. Ora, tudo isto concorre para o afastamento dos cidadãos, quer em relação à política, quer ao próprio jornalismo político.

Importa ressalvar que os jornalistas não estão inocentes. Muitas vezes, os jornalistas deixam-se seduzir pelos jogos de poder e pelos maquiavelismos da dinâmica política, acabando por funcionar como peças de engrenagem em campanhas de manipulação informativa. Isto acontece, por exemplo, quando são instrumentalizados pelas fontes não identificadas, de quem se tornam meras caixas de ressonância. Esta entorse à função informativa é explicada, em muitos casos, pela procura quase cega de exclusivos e "furos", sem que os jornalistas acautelem a veracidade do que lhes é dito pelas fontes. Por fim, a hegemonia informativa da televisão acentuou o culto da imagem dos políticos; culto esse 
alimentado quer pelos spin doctors quer pelos próprios jornalistas, que privilegiam quem na política tem boa figura e é bom falante.

É, aliás, na especial relação que os spin doctors têm com os jornalistas que, em boa medida, os primeiros se distinguem dos assessores de imprensa generalistas. Embora ambos privilegiem a transmissão de informação favorável sobre quem representam, assessores de imprensa e spin doctors adotam diferentes métodos de persuasão dos media. Os assessores utilizam as tradicionais técnicas de assessoria de imprensa (press releases, comunicados, conferências de imprensa, newsletters etc.), enquanto os spin doctors preferem a fuga-plantada através do contacto pessoal com os jornalistas. Atuam, portanto, numa base de maior informalidade, discrição e calculismo. Desta forma, não só tem uma acrescida capacidade de pressão sobre os jornalistas como suas ações dificilmente deixam rasto.

A dúvida que emerge de tudo isto prende-se, justamente, com a capacidade dos jornalistas responderem à crescente sofisticação do spin doctoring. Ou seja, se o jornalismo terá uma firewall capaz de filtrar o que é informação credível, verdadeira e de interesse público proveniente das fontes, protegendo-se assim de sofisticados "vírus" potencialmente contaminadores das notícias. Mais: é lícito imaginar um cenário em que, por via da expansão das redes sociais e do "jornalismo cidadão", as fontes passem a comunicar diretamente com seus públicos, sem a intermediação dos media. Isso corresponderia à subalternização do jornalismo, com óbvias consequências para a democracia.

\section{Referências}

AELST, P. V.; SHEAFER, T.; STANYER, J. The Personalization of Mediated Political Communication: Operationalizing Key Concepts for the Analysis of News Content. In: International Communication Association Conference. Boston: Internacional Communication Association, 2011.

AIRA FOIX, T.; PASTOR PÉREZ, L. Repensando las relaciones Política-Media. Hacia una teoría no anglosajona de la figura del 'spin' en comunicación política. In: III Congrés Internacional de l'Associació Espanyola d'Investigació de la Comunicació. Tarragona: Comunicació y Riesgo, 2012, pp. 1-19.

ALTHEIDE, D. L. Creating Reality: How TV news distorts events. London: SAGE Publications, 1976.

ANDREWS, L. Spin: from tactic to tabloid. Journal of Public Affairs, v. 6, n. 1, p. 31-45, 2006.

BLUMENTHAL, S. The Permanent Campaign: Inside the world os elite political operatives. Boston: Beacon Press, 1980.

BLUMLER, J. G. Elections, the media and the modern publicity process. In: FERGUSON, M. (Ed.). Public Communication - The new imperatives. London and New York: SAGE Publications, 1990. pp. 101-113. 
BROOKS, D. How to increase media coverage for your product or service by understanding and meeting shared responsibilities with the media. Public Relations Quarterly, v. Winter (1999), p. 26-30, 1999.

BROWN, R. Rethinking government-Media relations: Towards a theory of spn. ECPR Conference. Marburg: University of Leeds, 2003.

CRAING, J. Spinning out of control? Guardian: 33 p. 1996.

DAVIS, A. Public Relations Democracy - Public Relations, politics and mass media in Britain. Manchester: Manchester University Press, 2002. p. 222

Public Relations and News Sources. In: COTTLE, S. (Ed.). News, Public Relations and Power. London: SAGE Publications, 2003, pp. 27-42.

DAYAN, D.; KATZ, E. Media Events: The live broadcasting of history. Cambridge, London: Harvard University Press, 1992.

ESSER, F.; REINEMANN, C.; FAN, D. Spin Doctoring in British and German Election Campaings. European Journal of Communication, v. 15, n. 2, pp. 209-239, 2000.

EWEN, S. PR! A social history of spin. New York: Basic Books, 1996.

FISHMAN, M. Manufacturing the news. Austin: University of Texas Press, 1980.

FITZWATER, M. Call the Briefing! Reagan and Bush: A decade with presidents and the press. Massachusetts: Adams Media Corporation, 1995.

FRANKLIN, B. A good day to bury bad news? Journalists, sources and the packaing of politics. In: COTTLE, S. (Ed.). News, Public Relations and Power. London: SAGE Publications, 2003, pp. 45-61.

Packaging politics: Political communications in Britain's media democracy. London: Arnold, 2004 [1994].

FRANKLIN, B.; AL, E. Key concepts in Public Relations. London: SAGE, 2009.

GABER, I. Government by spin: an analysis of the process. Media, Culture \& Society, v. 22, n. 4, pp. $507-$ 518 , July $1,2000$.

. Too much of a good thing: the 'problem' of political communications in a mass media democracy. Journal of Public Affairs, v. 7, n. 3, p. 219-234, 2007.

. The Slow Death of the Westminister lobby: collateral damage from the MPs' expenses scandal. MECCSA Annual Conference. London School of Economics: MECCSA, 2010.

GANS, H. J. Deciding What's News: A study of CBS Evening News, NBC Nightly News, Newsweek and Time. Evanston: Northwestern University Press, 1979.

GEWIRTZ, S.; DICKSON, M.; POWER, S. Unravelling a 'spun' policy: a case study of the constitutive role of 'spin' in the education policy process. Journal of Education Policy, v. 19, n. 3, pp. 321-342, 2004. 
GOLDING , P.; BENS, E. D.; MCQUAIL, D., Eds. Communication Theory and Research. London: SAGE Publications ed., 2005.

GREVE, F. Journalism In the Age of Pseudoreporting. Disponível em: http://niemanreports.org/articles/ journalism-in-the-age-of-pseudoreporting/, 2005. Acessado em 24 ago. 2015.

HARRIS, P. To Spin or not to Spin that is the Question: The Emergence of Modern Political Marketing. The Marketing Review, v. 2000, n. 1, pp. 1-19, 2000.

. Machiavelli, political marketing and reinventing government. European Journal of Marketing, v. 35, n. 9/10, pp. 1136-1154, 2001.

HAUSER, R. Os mailings no marketing directo. Men Martins: Edições CETOP, 1999.

HESS, S. The Government/Press Connection. Washington DC: The Brookings Institution, 1984.

JAMIESON, K. H. Dirty Politics: Deception, Distraction, and Democracy. New York: Oxford Univerity Press, 1992.

JONES, N. Doctors in the house. Guardian: 38 p. 1995.

KURTZ, H. Spin Cycle: How the white house and the media manipulate the news. New York: Touchstone, 1998.

LANGDON, J. Trust me, I'm not a doctor. Guardian: 24 p. 1995.

Spin, whores, spin. Guardian, p. 15, 9 August, 1996.

LOUW, E. The Media and Political Process. London: SAGE, 2005.

LOUW, E. The Media \& Political Process. London: SAGE, 2010.

MAAT, H. P. How promotional language in press releases is dealt with by journalists: Genre mixing or genre conflict? Journal of Business Communication, v. 44, n. 1, pp. 59-95, 2007.

MALTESE, J. A. Spin Control: The White House office of communications and the management of presidenctial news. Chapel Hill and London: The University of North Carolina Press, 1992.

MANNING, P. News and news sources: a critical introduction. London; Thousand Oaks: Sage Publications, 2001.

. News Sources, News Agencies and the Banking Crisis. MeCCSA Conference 2010. London School of Economics: London School of Economics: 25 p., 2010.

MCNAIR, B. An introduction to political communication. London: Routledge, 2003 [1995]. PR must die: spin, anti-spin and political public relations in the UK, 1997-2004. Journalism Studies, v. 5, n. 3, pp. 325-338, 2004

MENCHER, M. News Reporting and Writing. Dubeque: Wm. C. Brown Publishers, 1991 [1977].

MICHIE, D. The invisible persuaders: How britain's spin doctors manipulate the media. London: Bantam Press, 1998.

MILLER, D.; DINAN, W. A Century of Spin: How Public Relations Became the Cutting Edge of Corporate Power. London: Pluto, 2008.

OBORNE, P.; WALTERS, S. Alastair Campbell. London: Aurum, 2004. 
ORNSTEIN, N.; MANN, T. The Permanent Campaign and its Future. New York: The Brookings Institute and American Enterprise Institute, 2000.

PEARSON, M. Suppression, privacy, contempt and spin: Australia's struggle with censorship in a Wertern democracy. 7th AMSAR. Bangkok: Bond University: pp. 1-17, 2009.

PRESTON, P. Sinister conspiracy theories falling into a flat spin. Guardian: 7 p. 1996. Party free or party pris? Guardian: 28 p. 1997.

RESTON, J. Washington: An anti-Hokum campaign in 1956. The New York Times: 8 p., 1955.

Washington: Scientists and Statesmen - The Big Difference. The New York Times: 1961. . Mondale and the Democrats. The New York Times: 31 p., 1981a. Washington: Whant to do about begin? The New York Times: 31 p., $1981 \mathrm{~b}$.

RIBEIRO, V. Fontes Sofisticadas de Informação: Análise do produto jornalístico político da imprensa nacional diária de 1995 a 2005. Lisboa: Formal Press, 2009.

O Spin Doctoring em Portugal: Estudo sobre as fontes profissionais de informação que operam na Assembleia da República. 2013. 521 (PhD). Instituto de Ciências Sociais, Universidade do Minho, Braga. 2013.

RICHARDS, P. Be your own spin doctor: A practical guide to using the media. London: Politico's, 2005.

SABATO, L. J. Feeding frenzy: How attack journalism has transformed american politics. Baltimo: Lanahan Publishers, Inc, 1993.

SAFIRE, W. The debate and the spin doctors. The New York Times, October 21, 1984.

SCHLESINGER, P. Open Scotland? Journalists, spin doctors and lobbyists. Edinburgh: Edinburgh University Press, 2001.

Is there a crisis in British journalism? Media, Culture \& Society, v. 28, n. 2, p. 299-307, 2006.

SCHMITZ, A. A.; KARAM, F. J. C. Os spin doctors e as fontes das notícias. Brazilian Journalism Research, v. 9, n. 1, pp. 98-115, 2013.

SCHROEDER, A. Presidencial Debates: Fifty Years od High-Risk TV. New York: Columbia University Press, 2008.

SERRANO, E. Spin doctoring e profissionalização da comunicação política. In: CORREIA, J. C.; FERREIRA, G. B., et al (Ed.). Conceitos de Comunicação Politica. Covilhã: LabCom Books, 2010. pp.91-98.

SEVIN, E.; KIMBALL, S.; KHALIL, M. Listening to President Obama: A Short Examination of Obama's Communication Practices. American Behavioral Scientist, v. 55, n. 6, pp. 803-812, 2011.

SEYMOUR-URE, C. Prime ministers and the media: Issues of power and control. London: Blackwell Publishing, 2003.

SIGAL, L. V. Reporters and officials: the organization and politics of newsmaking. Lexington: D. C. Heath, 1973. 
STANYER, J. The creation of political news: Television and British party political conferences. Brighton: Sussex Academy Press, 2001. Intimate Politics. Cambridge: Polity Press, 2013.

STARK, E. Postdebate presentation of candidate schemata: The spin doctor's prescription for impression management. 2000. (61). ProQuest Information \& Learning, US.

STREET, J. Mass media, politics \& democracy. Hampshire: Palgrave Macmillan, 2011.

SUMPTER, T.; TANKARD, J. W. The spin doctor: an alternative model of public relations. Public Relations Review, v. 20, n. 1, pp. 19-27, 1994.

TANKARD, J. W.; SUMPTER, R. Media Manipulation: The Use of the Term "Spin Doctor". Proceedings of the Annual Meeting of the Association for Education in Journalism and Mass Communication, Kansas City: 76th: Association for Education in Journalism and Mass Communication. 1993. pp.4-19.

THOMPSON, J. B. Political Scandal: Power and Visibility in the Media Age. Cambridge, UK: Polity, 2000.

TRAQUINA, N. As notícias. In: TRAQUINA, N. (Ed.). Jornalismo: Questões, Teorias e "Estórias". Lisboa: Vega, 1993a. pp.167-176. . Jornalismo: Questões, teorias e "estórias”. Lisboa: Vega, 1993 b.

TUCHMAN, G. Making news: a study in the construction of reality. New York: Free Press, 1978.

TUNSTALL, J. The Westminster Lobby Correspondents: Sociological Study Of National Political Journalism. London: Routledge \& Kegan Paul, 1970.

. Journalists at work. Specialist correspondents: their news organizations, news sources, and competitor-colleagues. London: Sage Publications, 1974.

VILLAFAÑE, J. Imagem positiva. Lisboa: Sílabo, 1993.

WHITE, M. Making a name in politics. Guardian: 39 p. 1996.

YANTAO, B. Interpretation of "spin doctoring". International Journal of Humanities and Social Science, v. 2, n. 5, pp. 123-126, March, 2012. 
